\title{
Optimal Estimation of the Parameters of Linear Periodically Time-varying Systems
}

\author{
Kazys KAZLAUSKAS \\ Institute of Mathematics and Informatics, Vilnius Pedagogical University \\ Akademijos 4, LT-2021 Vilnius, Lithuania \\ e-mail: kazlausk@ktl.mii.lt
}

Received: January 2003

\begin{abstract}
This paper discusses the linear periodically time-varying (LPTV) system parameter estimation using a block approach. An block algorithm is proposed for optimal estimation of the parameters of LPTV system from the input sequence and the output sequence corrupted by additive Gaussianly distributed noise. In the proposed method, the least squares error criterion has been used.The algorithm provides a useful computational tool based on an appropriate theoretical foundation for parameter estimation of linear time-invariant (LTI) systems from input and output data. Simulation results are presented that demonstrate the performance of the approach.
\end{abstract}

Key words: parameter estimation, least squares, block approach, linear periodically time-varying systems, numerical simulation.

\section{Introduction}

The problem of estimating parameters from noisy observed data has a long history in engineering and experimental science in general. These problems have been analysed in a large number works in many different fields (Ljung, 1999; Iserman, 1981; Eykhoff, 1974). Among many models, the autoregressive moving average (ARMA) model is one of the most effective and practical. When the observations and the unknown parameters are related by a linear model, and a stochastic setting is assumed, then the application of the maximum likelihood principle (Berger and Wolpert, 1988) leads to the well known leastsquares parameter estimate. Main reason for the popularity of ARMA modeling is that it is possible to obtain good estimates of the unknown parameters by solving a simultaneous set of linear equations. Many well-known techniques developed for statistical time series analysis have been used successfully in the deterministic case (Jackon, 1986).

A linear periodically time-varying discrete-time system with period $L$ is a system for which a shift in the input sequence by $L$ samples results in a shift of $L$ samples in the output sequence. These systems are a generalization of linear time-invariant (LTI) systems and are used frequently in control systems, signal processing and digital communications (Mehr and Chen, 2001; Shenoy et al., 1994; Vaidyanathan, 1993). There are many ways to represent LPTV systems: common ones include difference equations or state-space 
models with periodically time-varying coefficients, equivalent linear time-invariant models obtained by the blocking technique. For an LTI system, we can relate the inputs and outputs of the system by a transfer matrix. For a LPTV system, we may use the block model of the system (Meyer and Burrus, 1975; Chen and Qiu, 1997; Kazlauskas, 1997).

This paper deals with the problem of estimating the parameters of an LPTV system. The least squares fitting error has been chosen as the objective optimality criterion. Several simulation examples demonstrate the performance of the proposed approach.

The paper is arranged as follows: in Section 2, the problem is formulated. In Section 3, the block model is defined. In Section 4, the nonrecursive estimation procedure is presented. In Section 5, several simulation examples are given. Finally, in Section 6, the paper is concluded with a discussion on the proposed algorithm.

\section{Problem Formulation}

It is assumed that a LPTV system is causal, linear with input sequence $x(k), k=0,1, \ldots$ and output sequence $u(k), k=0,1, \ldots$, so that it can be described by a linear difference equation

$$
u(k)=\sum_{i=0}^{N} \beta_{i}(k) x(k-i)-\sum_{j=1}^{M} \alpha_{j}(k) u(k-j), \quad k=0,1, \ldots ; N \leqslant M .
$$

The measured output $y(k)$ is assumed to be contaminated with the measurement noise $n(k)$

$$
y(k)=u(k)+n(k) .
$$

Equation (1) is $L$-periodic, i.e., parameters of LPTV system satisfies conditions $\alpha_{j}(k)=$ $\alpha_{j}(k+L), \beta_{i}(k)=\beta_{i}(k+L)$ for all $k=0,1, \ldots ; L$ is periodicity, $L=2,3, \ldots$.

A noise $n(k)$ is a nonmeasurable, normally distributed, statistically independent (discrete white noise) with $E\{n(k)\}=0, E\{n(k) n(k+\tau)\}=\sigma_{n}^{2} \delta(\tau)$, where $E\{n(k)\}$ is a mean value, $\sigma_{n}^{2}$ is the variance and $\delta(\tau)$ is the Kronecker delta function. The basis of LPTV parameter estimation is the set of data $\{x(0), x(1), \ldots, x(T), y(0), y(1), \ldots$, $y(T)\}$ of observations of the input sequence $\{x(k)\}$ and the noisy output sequence $\{(y(k)\}, k=0,1, \ldots, T$.

The purpose of the paper is to investigate the block parameter estimation approach in the case of additive noise $n(k), k=0,1, \ldots$, acting on the output of the LPTV system (1) to be estimated.

\section{Block Model}

The objective of parameter estimation is to estimate the LPTV system parameters in (1) based on measured sequences $x(k)$ and $y(k)$. It is assumed that the $M$ and $N$ are known 
a priori. If this is not the case they can be determined by order search methods (Iserman, 1974). The noise $n(k)$ is assumed to be stationary.

Consider that the input sequence $x(k)$ and the output sequence $y(k)$ of the LPTV system are measured for $k=0,1, \ldots, T$. The model of the LPTV system can be described by a linear difference equation

$$
y(k)+\sum_{j=1}^{M} a_{j}(k) y(k-j)-\sum_{i=0}^{N} b_{i}(k) x(k-i)=e(k), \quad k=0,1, \ldots ; N \leqslant M,
$$

where $a_{j}(k)=a_{j}(k+L)$ and $b_{i}(k)=b_{i}(k+L)$ - parameters of the model. The equation error (residual) $e(k)$ arises from the noise contaminated output $y(k)$ and from erroneous parameter estimates.

Replacing $k$ by $l+(m-1) L$ and blocking the input sequence $x(k)$ and the output sequence $y(k)$, we obtain the equation of the block model

$$
\begin{aligned}
y(l+(m-1) L) & +\sum_{j=1}^{M} a_{j}(l) y(l+(m-1) L-j) \\
& -\sum_{i=0}^{N} b_{i}(l) x(l+(m-1) L-i)=e(l+(m-1) L),
\end{aligned}
$$

or

$$
\begin{aligned}
y(l+(m-1) L)= & \sum_{i=0}^{N} b_{i}(l) x(l+(m-1) L-i) \\
& -\sum_{j=1}^{M} a_{j}(l) y(l+(m-1) L-j)+e(l+(m-1) L),
\end{aligned}
$$

where $l=M+1, \ldots, M+L ; m=1,2, \ldots, p ; p=f i x((T-M-1) / L)-$ rounds the $(T-M-1) / L$ to the nearest integer towards zero.

The system of linear equations (2) can be expressed in a matrix form as follows:

$$
\bar{y}(l)=A(l) \theta(l)+\bar{e}(l), \quad l=M+1, \ldots, M+L,
$$

where

$$
\bar{y}(l)=[y(l), y(l+L), \ldots, y(l+(m-1) L), \ldots, y(l+(p-1) L)]^{T}
$$

is a $p$-element vector,

$$
\theta(l)=\left[b_{0}(l), \ldots, b_{i}(l), \ldots, b_{N}(l), a_{1}(l), \ldots, a_{j}(l), \ldots, a_{M}(l)\right]^{T}
$$


is a $(N+M+1)$-element vector,

$$
\bar{e}(l)=[e(l), e(l+L), \ldots, e(l+(m-1) L), \ldots, e(l+(p-1) L)]^{T}
$$

is a $p$-element vector,

$$
\begin{aligned}
A(l)= \\
=\left[\begin{array}{l}
x(l), \ldots, x(l-i), \ldots, x(l-N),-y(l-1), \ldots,-y(l-j), \ldots,-y(l-M) \\
\ldots \\
x(l+(m-1) L), \ldots, x(l+(m-1) L-i), \ldots, x(l+(m-1) L-N), \\
-y(l+(m-1) L-1), \ldots,-y(l+(m-1) L-j), \ldots,-y(l+(m-1) L-M) \\
\ldots \\
x(l+(p-1) L), \ldots, x(l+(p-1) L-i), \ldots, x(l+(p-1) L-N), \\
-y(l+(p-1) L-1), \ldots,-y(l+(p-1) L-j), \ldots,-y(l+(p-1) L-M
\end{array}\right]
\end{aligned}
$$

is a $(p \times(N+M+1))$ data matrix.

\section{Nonrecursive Estimation Procedure}

Define $x_{l}(m)=x(l+(m-1) L)$ and $y_{l}(m)=y(l+(m-1) L)$, then errors of the block model (2)

$$
\begin{gathered}
e_{l}(m)=y_{l}(m)+\sum_{j=1}^{M} a_{j}(l) y_{l}(m-j)-\sum_{i=0}^{N} b_{i}(l) x_{l}(m-i), \\
m=1,2, \ldots ; l=M+1, \ldots, M+L
\end{gathered}
$$

where $e_{l}(m)=e(l+(m-1) L)$.

Minimization of the loss functions

$$
V_{l}=\min _{\theta(l)} \bar{e}^{T}(l) \bar{e}(l)=\sum_{m=1}^{p} e^{2}(l+(m-1) L), \quad l=M+1, \ldots, M+L,
$$

and therefore $\left.\frac{\partial V_{l}}{\partial \theta(l)}\right|_{\theta(l)=\hat{\theta}(l)}=0, l=M+1, \ldots, M+L$ results in the optimal parameter estimation. Assuming that $A$ is full rank, the least squares solution of the overdetermined system of linear equations (2) is

$$
\hat{\theta}(l)=\left(A^{T}(l) A(l)\right)^{-1} A^{T}(l) \bar{y}(l), \quad l=M+1, \ldots, M+L .
$$

where $\hat{\theta}(l)=\left[\hat{b}_{0}(l), \ldots, \hat{b}_{i}(l), \ldots, \hat{b}_{N}(l), \hat{a}_{1}(l), \ldots, \hat{a}_{j}(l), \ldots, \hat{a}_{M}(l)\right]^{T}$ are the optimal estimates.

The parameter estimation problem has been transformed into an one-dimensional minimization problem (8) for $L$ sets parameters of the LPTV system. This is nonrecursive parameter estimation as the parameter estimates are obtained only after measuring 
and storing of all signal values. Apart from using the standard least squares approach, the overdetermined system of equations (3) can be solved using the total least squares method (Golub and Van Loan, 1983). This method assumes that there are estimation errors in the elements of both $A$ and $\bar{y}$. $A$ and $\bar{y}$ are then modified so that the rank of the extended matrix $[A \bar{y}]$ equals to rank of $A$.

Using the backward time-shift operator $z^{-1}$ such that $z^{-1} y(k)=y(k-1)$, the block model (2) can be described in the form

$$
\begin{array}{r}
e_{l}(m)=A_{l}\left(z^{-1}\right) y_{l}(m)-B_{l}\left(z^{-1}\right) x_{l}(m), \\
\quad l=M+1, \ldots M+L, m=1,2, \ldots,
\end{array}
$$

where

$$
\begin{aligned}
& A_{l}\left(z^{-1}\right)=1+a_{1}(l) z^{-1}+\ldots+a_{M}(l) z^{-M} \\
& B_{l}\left(z^{-1}\right)=b_{0}(l)+b_{1}(l) z^{-1}+\ldots+b_{N}(l) z^{-N}
\end{aligned}
$$

Operators $A_{l}\left(z^{-1}\right)$ and $B_{l}\left(z^{-1}\right)$ depend on parameters $a_{i}(l)$ and $b_{j}(l)$. The errors $e_{l}(m)$ of the block model are linear functions of the parameters.

The block estimation of the LPTV system parameters is shown in Fig. 1.The input and the output registers reduce (decimate) the sampling rate of the input sequence $x(k)$ and of the output sequence $y(k)$. The sampling rate reduction is achieved by forming the subsequences $x_{M+i}(m)$ and $y_{M+i}(m), i=1,2, \ldots, L$ and by saving every $L$ th sample of the sequences $x(k)$ and $y(k)$. The decimation factor is equal to the periodicity of the LPTV system, i.e., to the block length $L$ of sequences $x(k)$ and $y(k)$. The subsequencies $x_{M+i}(m)$ and $y_{M+i}(m), i=1,2, \ldots, L$ at the outputs of registers are used for the parameter estimation. The parameter estimation we begin at the time moment $l=M+1$, where $M$ is the order of the LPTV system. The estimation procedure can be accomplished in a parallel manner for $l=M+1, \ldots, M+L$ (see Fig. 1).

In case the LPTV system periodicity $L$ is unknown, we can repeat the parameter estimation process with different periodicity values $L^{*}=2,3$, and so on. If $L^{*} \neq L$ ( $L$ is a true system periodicity), then we obtain large values of loss functions (8) and bad parameter estimates, because the elements of the data matrix $A(l)$ are not such as

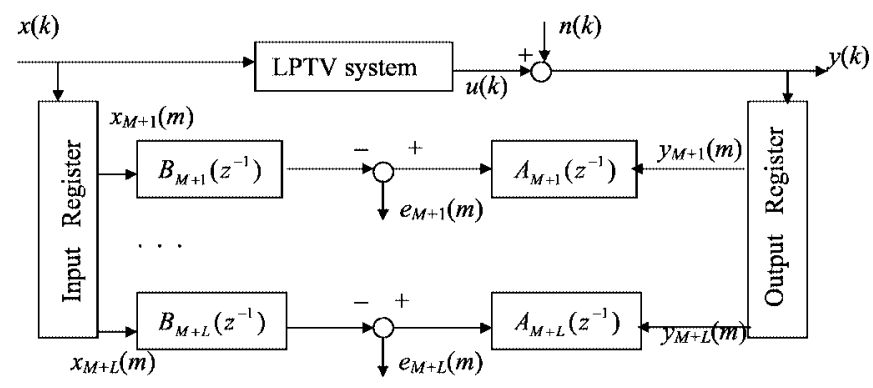

Fig. 1. The block estimation of the LPTV system parameters. 
they must be in (6). In case $L^{*}=L$, we obtain small values of loss functions (8) and optimal parameter estimates because the elements of the data matrix $A(l)$ are just like they must be in (6). Then, by repeating the estimation process with different values of the periodicity $L^{*}$, calculating loss functions (8), and comparing these values, we can estimate the true value of the LPTV system periodicity $L$.

\section{Numerical Simulation}

In this section we apply the described method to an example of LPTV system. The LPTV system to be simulated is described by a linear difference equation

$$
y(k)=\sum_{i=0}^{2} \beta_{i}(k) x(k-i)-\sum_{j=1}^{2} \alpha_{j}(k) y(k-j)+\lambda n(k), \quad k=0,1, \ldots,
$$

where

$$
\begin{aligned}
& \beta_{0}(0)=1, \beta_{0}(1)=1.2, \beta_{0}(2)=1.5, \beta_{1}(0)=2, \beta_{1}(1)=2.2 \\
& \beta_{1}(2)=2.5, \beta_{2}(0)=3, \beta_{2}(1)=3.2, \beta_{2}(2)=3.5, \alpha_{1}(0)=-1.1197 \\
& \alpha_{1}(1)=-1.5, \alpha_{1}(2)=-1.036, \alpha_{2}(0)=0.3012, \alpha_{2}(1)=0.7, \alpha_{2}(2)=0.2636
\end{aligned}
$$

The periodicity $L$ of the LPTV system (1) is equal to 3 . The noise sequence $n(k)$ is generated as a zero-mean, unit-variance white noise sequence with a Gaussian distribution. $\lambda$ is a constant that determines the intensity of additive noise $n(k)$.

The sequences, including that of the noise $n(k), k=0,1, \ldots, 500$ where generated using the MATLAB functions. For calculation of the LPTV system output we used MATLAB $m$-file PERIOD. The matrix (6) was formed by using $m$-file MATRICA.

The performance of the estimated model is summarized in Table 1, in which signal to noise ratio (SNR) is defined as $S N R=20 \log _{10} \frac{\sigma_{u}}{\sigma_{n}}$, where $\sigma_{u}$ - standard deviation (std) of the LPTV system output without noise, $\sigma_{n}$ - standard deviation of the noise $n(k)$. In Table $1 \alpha$ and $\beta$ are true parameters of the LPTV system and $\hat{a}$ and $\hat{b}$ are averaged estimated parameters of the model.

For calculation of averaged estimated values $\hat{a}$ and $\hat{b}$ we repeated estimation procedure (9) 500 times, obtained 500 sets of estimated values, then calculated mean and standard deviation of the estimated values for $\mathrm{SNR}=43,28,22,16$ and $12 \mathrm{~dB}$.

In Fig. 2 we show how the estimation quality of the LPTV system parameters depends on the number of processed observations for $\mathrm{SNR}=12 \mathrm{~dB}$. We defined a measure of the parameter estimation quality as:

$$
B 0=\frac{\left|\beta_{0}(0)-\hat{b}_{0}(0)\right|}{\left|\beta_{0}(0)\right|} \cdot 100 \%, \quad A 1=\frac{\left|\alpha_{1}(0)-\hat{a}_{1}(0)\right|}{\left|\alpha_{1}(0)\right|} \cdot 100 \%,
$$

and so on, where $\hat{b}_{0}(0), \hat{a}_{1}(0)$ denote averaged estimated parameters and $\beta_{0}(0), \alpha_{1}(0)$ denote true parameters of the LPTV system at time moment 0 . 
Table 1

LPTV system parameter estimation using block model. True parameters and averaged estimated parameters of the LPTV system (11) via SNR (dB)

\begin{tabular}{|c|c|c|c|c|c|c|}
\hline $\begin{array}{l}\text { True parame- } \\
\text { ter values }\end{array}$ & $\beta_{0}(0)=1$ & $\beta_{1}(0)=2$ & $\beta_{2}(0)=3$ & $\begin{array}{l}\alpha_{1}(0)= \\
-1.1197\end{array}$ & $\begin{array}{l}\alpha_{2}(0)= \\
0.3012\end{array}$ & $\begin{array}{l}\text { SNR } \\
(\mathrm{dB})\end{array}$ \\
\hline $\begin{array}{l}\text { Estimated } \\
\text { values }\end{array}$ & $\hat{b}_{0}(0)$ & $\hat{b}_{1}(0)$ & $\hat{b}_{2}(0)$ & $\hat{a}_{1}(0)$ & $\hat{a}_{2}(0)$ & \\
\hline mean & 1.0026 & 2.0026 & 3.0011 & -1.1188 & 0.3004 & 43 \\
\hline $\begin{array}{l}\text { std } \\
\text { mean }\end{array}$ & $\begin{array}{l}0.0341 \\
1.0082\end{array}$ & $\begin{array}{l}0.0379 \\
2.0281\end{array}$ & $\begin{array}{l}0.0322 \\
3.0510\end{array}$ & $\begin{array}{r}0.0071 \\
-1.0997\end{array}$ & $\begin{array}{l}0.0072 \\
0.2827\end{array}$ & 28 \\
\hline std & 0.1267 & 0.1929 & 0.1658 & 0.0453 & 0.0370 & \\
\hline mean & 1.0109 & 2.1205 & 3.1723 & -1.0473 & 0.2346 & 22 \\
\hline std & 0.2510 & 0.2847 & 0.2963 & 0.0557 & 0.0544 & \\
\hline mean & 0.9939 & 2.3361 & 3.5897 & -0.9072 & 0.1060 & 16 \\
\hline std & 0.4370 & 0.5232 & 0.7051 & 0.1295 & 0.1138 & \\
\hline mean & 0.9995 & 2.5328 & 3.9647 & -0.7579 & -0.0151 & 12 \\
\hline std & 0.7933 & 0.9071 & 0.8420 & 0.1444 & 0.1324 & \\
\hline $\begin{array}{l}\text { True parame- } \\
\text { ter values }\end{array}$ & $\beta_{0}(1)=1.2$ & $\beta_{1}(1)=2.2$ & $\beta_{2}(1)=3.2$ & $\alpha_{1}(1)=-1.5$ & $\alpha_{2}(1)=0.7$ & \\
\hline $\begin{array}{l}\text { Estimated } \\
\text { values }\end{array}$ & $\hat{b}_{0}(1)$ & $\hat{b}_{1}(1)$ & $\hat{b}_{2}(1)$ & $\hat{a}_{1}(1)$ & $\hat{a}_{2}(1)$ & \\
\hline mean & 1.1983 & 2.1976 & 3.2006 & -1.4990 & 0.6997 & 43 \\
\hline std & 0.0754 & 0.0824 & 0.0455 & 0.0164 & 0.0168 & \\
\hline mean & 1.2032 & 2.2618 & 3.2880 & -1.4625 & 0.6654 & 28 \\
\hline std & 0.1890 & 0.1957 & 0.2112 & 0.0432 & 0.0429 & \\
\hline mean & 1.1739 & 2.3298 & 3.4876 & -1.3712 & 0.5829 & 22 \\
\hline std & 0.3531 & 0.3460 & 0.3442 & 0.0814 & 0.0778 & \\
\hline mean & 1.1687 & 2.6061 & 4.0788 & -1.1184 & 0.3461 & 16 \\
\hline std & 0.7193 & 0.5577 & 0.9445 & 0.1850 & 0.1556 & \\
\hline mean & 1.2662 & 2.8081 & 4.6689 & -0.8914 & 0.1482 & 12 \\
\hline std & 0.8800 & 0.9134 & 1.2331 & 0.1792 & 0.1676 & \\
\hline $\begin{array}{l}\text { True parame- } \\
\text { ter values }\end{array}$ & $\beta_{0}(2)=1.5$ & $\beta_{1}(2)=2.5$ & $\beta_{2}(2)=3.5$ & $\begin{array}{l}\alpha_{1}(2)= \\
-1.036\end{array}$ & $\begin{array}{c}\alpha_{2}(2)= \\
0.264\end{array}$ & \\
\hline $\begin{array}{l}\text { Estimated } \\
\text { values } \\
\end{array}$ & $\hat{b}_{0}(2)$ & $\hat{b}_{1}(2)$ & $\hat{b}_{2}(2)$ & $\hat{a}_{1}(2)$ & $\hat{a}_{2}(2)$ & \\
\hline mean & 1.5010 & 2.5005 & 3.5008 & -1.0358 & 0.2635 & 43 \\
\hline std & 0.0232 & 0.0248 & 0.0335 & 0.0052 & 0.0054 & \\
\hline mean & 1.5100 & 2.5125 & 3.5353 & -1.0239 & 0.2507 & 28 \\
\hline std & 0.1327 & 0.1607 & 0.1407 & 0.0221 & 0.0228 & \\
\hline mean & 1.4853 & 2.5572 & 3.6224 & -0.9950 & 0.2248 & 22 \\
\hline std & 0.2524 & 0.2484 & 0.3270 & 0.0433 & 0.0447 & \\
\hline mean & 1.4998 & 2.6579 & 3.8708 & -0.8998 & 0.1343 & 16 \\
\hline std & 0.5572 & 0.5645 & 0.5186 & 0.0815 & 0.0803 & \\
\hline mean & 1.4563 & 2.8607 & 4.2015 & -0.7816 & 0.0259 & 12 \\
\hline std & 0.6437 & 0.7949 & 0.8443 & 0.1068 & 0.1050 & \\
\hline
\end{tabular}



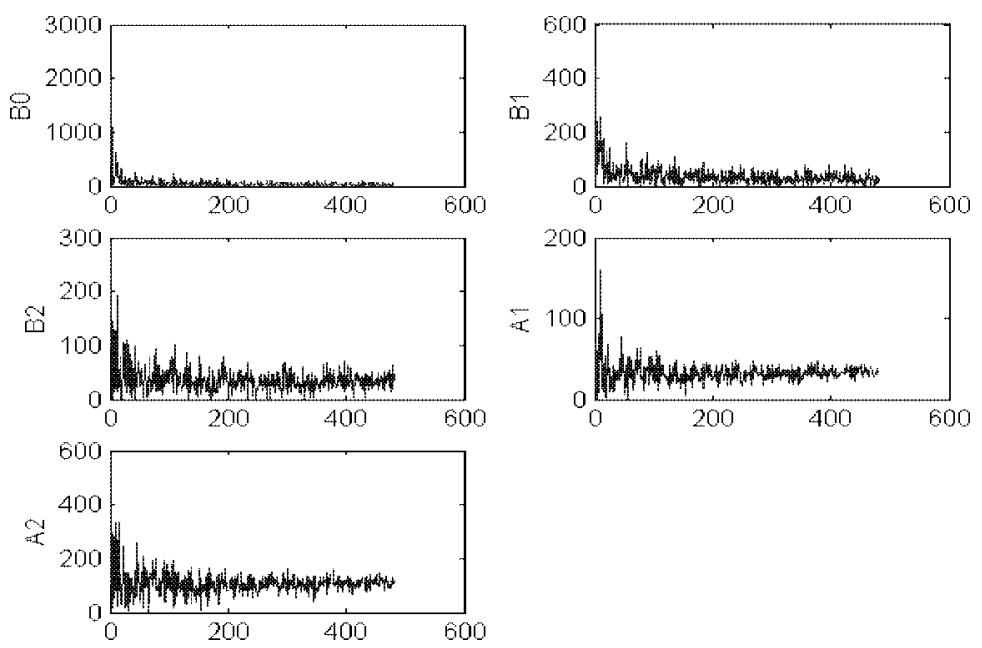

Fig. 2. The quality of the LPTV system parameter estimation vs the number of processed observations. $\mathrm{SNR}=12 \mathrm{~dB}$.

The impulse responses of LPTV system (full lines) and impulse responses of the estimated system (dotted lines) for time moments 0,1 and 2 in case $\mathrm{SNR}=12 \mathrm{~dB}$ are shown in Fig. 3.
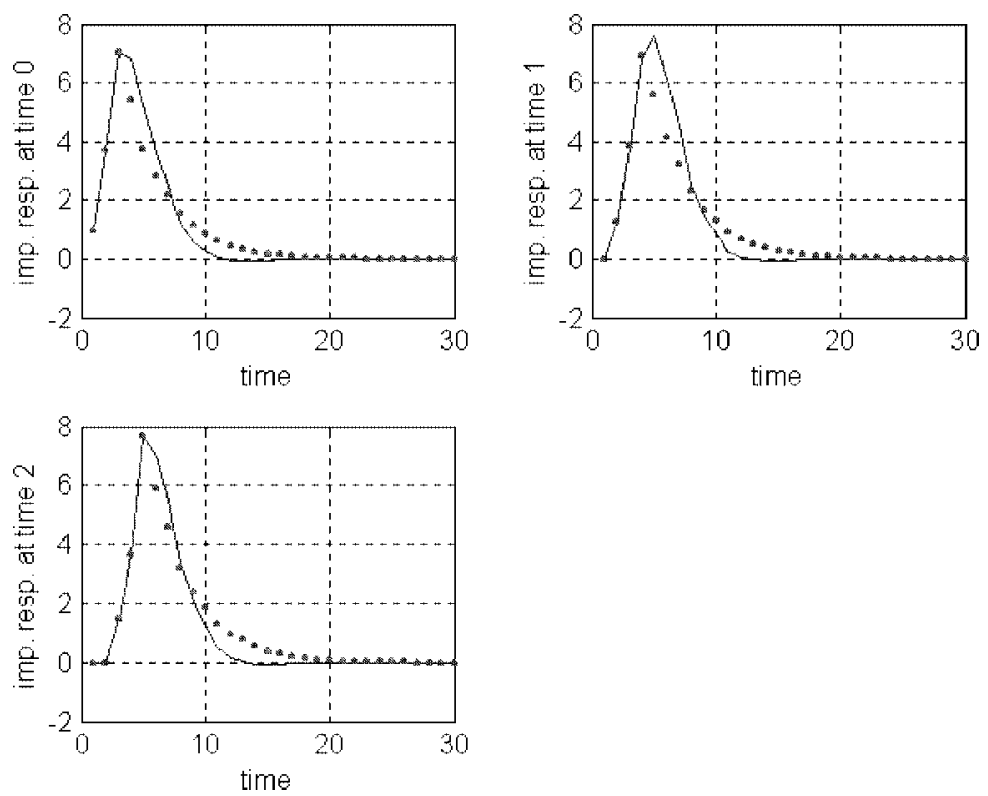

Fig. 3. Impulse responses of the LPTV system (11) (full lines) and the impulse responses of the estimated LPTV system (dotted lines). $\mathrm{SNR}=12 \mathrm{~dB}$. 

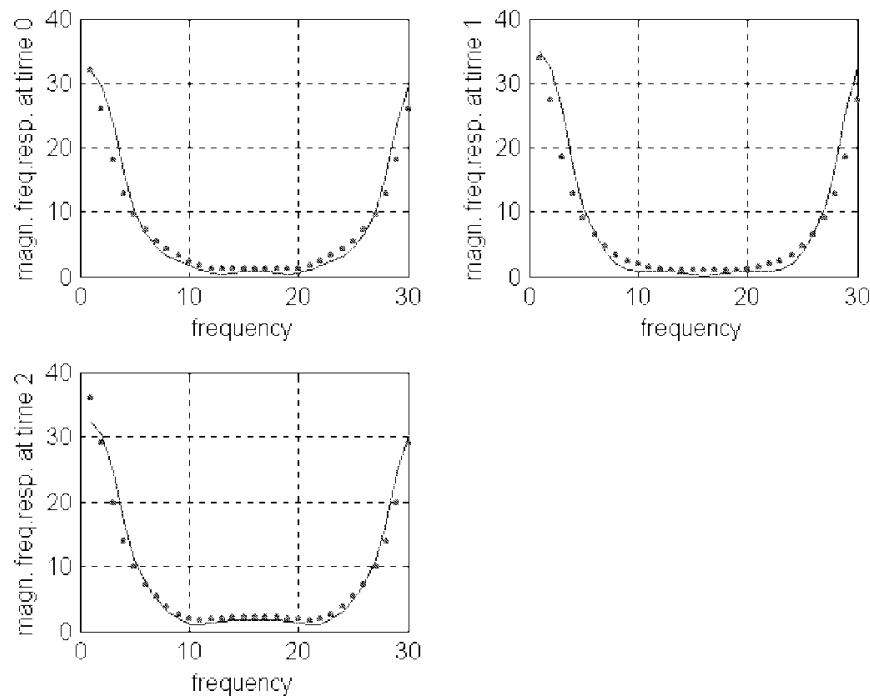

Fig. 4. Magnitude frequency responses of the LPTV system (11) (full lines) and magnitude frequency responses of the estimated LPTV system (dotted lines). SNR $=12 \mathrm{~dB}$.

In Fig. 4 we show magnitude of the frequency responses of LPTV system (full lines) and magnitude of the frequency responses of the estimated system (dotted lines) for 0,1 , and 2 time moments in case SNR $=12 \mathrm{~dB}$.

\section{Conclusion}

We have discussed a block parameter estimation method for linear periodically timevarying systems. Its performance strongly depends on the noise level and does not provide satisfactory parameter estimation results when the noise level is high. The estimated values are seen to be close to the true parameter values at high SNR. This property can be confirmed by the analysis of the simulation results of Table 1 . We show that the parallel parameter estimation structure can be realized. If periodicity $L=1$, the block method reduces to the conventional LTI system parameter estimation method. The results of numerical simulation of the LPTV system by computer show efficiency of the proposed approach.

\section{Acknowledgements}

Author thanks to the anonymous reviewer whose comments served for improving the paper. 


\section{References}

Berger, J.O., and R. Wolpert (1988). The Likelihood Principle. Hayward, CA, Institute of Mathematical Statistics.

Chen, T., and L. Qiu (1997). Linear periodically time-varying discrete-time systems: Aliasing and LTI approximations. Syst. Contr. Lett., 30, 225-235.

Eykhoff, P. (1974). System Identification. London, John Wiley.

Golub, G., and C. Van Loan (1983). Matrix Computations. Baltimore, MD, Johns Hopkins University Press.

Iserman, R. (1981). Digital Control Systems. Springer-Verlag, Berlin, Heidelberg.

Iserman, R. (1974). Proze $\beta$ identifikation. Berlin, Springer.

Jackson, L.B. (1986). Digital Filters and Signal Processing. Boston, Kluwer.

Kazlauskas, K.(1997). Pipelined-block models of linear discrete-time systems. Informatica, 8(2), 215-236.

Ljung, L. (1999). System Identification. Theory for the Users. Second edition. Prentice-Hall.

Mehr, A.S., and T. Chen (2001). On alias-component matrices of discrete-time linear periodically time-varying systems. Signal Processing Letters, 8(4), 114-116.

Meyer, R.A., and C.S. Burrus (1975). A unified analysis of multirate and periodically time-varying digital filters. IEEE Trans. Circuits Syst., 22, 162-168.

Shenoy, R.G., D. Burnside and T.W. Parks (1994). Linear periodic systems and multirate filter design. IEEE Trans. Signal Processing, 42, 2242-2256.

Vaidyanathan, P.P. (1993). Multirate Systems and Filter Banks. Englewood Cliffs, NJ, Prentice-Hall.

K. Kazlauskas received PhD degree from Kaunas Polytechnic Institute and Doctor habilitus degree from Institute of Mathematics and Informatics and Vytautas Magnus University. He is a senior researcher of the Recognition Processes Department at the Institute of Mathematics and Informatics and professor at the Informatics Department of Vilnius Pedagogical University. His research interests include design of concurrent algorithm and architectures for signal processing, and computer aided design of signal processing systems.

\section{Tiesiniu periodiškai kintamu sistemu parametru optimalus ivertinimas}

\section{Kazys KAZLAUSKAS}

Nagrinejjamas tiesiniu periodiškai kintamu sistemu blokinis parametru ivertinimo metodas. Šio metodo efektyvumas labai priklauso nuo triukšmo lygio. Jei triukšmo lygis žemas, tai gauname parametru iverčius, artimus sistemos parametrams. Parodyta, kad parametru įverčius galima apskaičiuoti lygiagrečiai. Jei sistemos periodiškumas lygus vienetui, tai blokinis metodas sutampa su tiesiniu pastovių sistemų parametrų įvertinimo metodu. Modeliavimo rezultatai parodo blokinio metodo efektyvumą. 